\title{
Biogeoquímica dos elementos terras raras na Província Estanífera de Pitinga (AM)
}

\author{
Maria do Carmo Lima e Cunha ${ }^{1}$, Vitor Paulo Pereira ${ }^{1}$, Artur César Bastos Neto ${ }^{1}$, \\ Lauro Valentim Stoll Nardi ${ }^{1}$, Milton Luiz Laquintinie Formoso ${ }^{1}$ \& Egydio Menegotto ${ }^{1}$
}

\begin{abstract}
Resumo A espécie vegetal Ampelozizyphus amazonicus Ducke (Família Rhamnaceae) foi escolhida como meio de amostragem nas superfícies lateríticas da Mina Pitnga, região amazônica, com o objetivo de se estudar o comportamento biogeoquímico dos elementos Terras Raras (ETR) nos solos derivados de rochas graníticas e vulcânicas ocorrentes na área da mina. Os resultados mostraram que a espécie $A$. amazonicus concentra valores significativos de ETR, predominantemente quando ocorrente nos solos derivados de rochas vulcânicas e reflete o padrão herdado da rocha mãe. Além disso, variações no padrão biogeoquímico dos ETR, resultantes do fracionamento dos elementos da série, como o efeito tétrade, foram também detectadas.
\end{abstract}

Palavras-chave: elementos terras raras, biogeoquímica, região amazônica, Ampelozizyphus amazonicus.

\begin{abstract}
Biogeochemistry of ree elements from Pitinga Tin Province (AM). The vegetal species Ampelozizyphus amazonicus Ducke (Rhamnaceae Family) was chosen as sampling media in the lateritic surfaces of the Pitinga Mine, Amazon region, with the purpose to study the biogeochemical behavior of the REE elements in soils derived from granitic and volcanic rocks. The results showed that the species A. amazonicus concentrates predominantly significant values of REE over volcanic soils and reflects the pattern inherited from the source rock. Some variations resultant from fractionation of the elements of the series, such as the tetrad effect, was also detected in the REE biogeochemical patterns.
\end{abstract}

Keywords: REE biogeochemistry, lateritic surface, Amazon region, Ampelozizyphus amazonicus.

INTRODUÇÃO Ainda que a literatura contenha inúmeras informações relativas à transferência das espécies químicas do solo para a planta, pouco é sabido sobre o comportamento biogeoquímico dos elementos Terras Raras neste processo.

Sob condições naturais os vegetais geralmente absorvem quantidades mínimas de ETR, com concentrações variando entre 1 e $45 \mathrm{ppm}$, em peso de cinzas (Kabata-Pendias e Pendias 1984). Isto porque, embora estes elementos possam ser mobilizados por fluidos hidrotermais e/ou sofrer remobilização em superfície durante os processos de formação dos solos (Nesbitt 1979, Topp et al. 1984, Lottermoser 1990), nas rochas eles se concentram em minerais acessórios e são preferencialmente pouco móveis (Henderson 1984). Entretanto, algumas espécies vegetais são capazes de acumular altos teores, apesar da baixa solubilidade dos ETR (Milton, Murata, Knetchel1944); Laul \& Weimer 1982 (apud Evans 1990).

Os primeiros registros relativos ao transporte e acúmulo de ETR em tecidos vegetais são reportados por Robinson, Bastron, Murata (1958), seguido pelos trabalhos de Dunn (1983b) e Markert et al. (1989). No entanto, o conhecimento sobre a mobilidade que proporciona a biodisponibilidade dos ETR e seu fracionamento, induzido por transferência para as plantas, são ainda frutos de hipóteses opostas ou divergentes.

Nos países orientais, em especial na China, a bio- geoquímica dos ETR tem sido motivo de pesquisas mais aprofundadas visto que o amplo uso desses elementos na agricultura vem causando um acúmulo excessivo no solo, o que pode resultar em danos ambientais pelo desconhecimento de seus efeitos no meio e, por conseqüência, nos organismos vivos (Ding et al. 2005, Wang et al. 2001, Brioschi et al. 2009). Neste sentido, a biogeoquímica pode contribuir para um melhor entendimento do comportamento geoquímico dos ETR, uma vez que as plantas, ao absorver as soluções do solo, refletem a mobilidade dos elementos químicos próximo à rizosfera.

No que se refere à bioprospecção, são poucas as referências sobre a utilização da vegetação como indicadora de concentrações anômalas de ETR em ambientes supergênicos.

No Brasil, um exemplo de caso ocorre no Depósito de Pau-a-Pique, sudoeste do Estado de Mato Grosso, onde a integração dos dados de ouro com dados de ETR, obtidos por litogeoquímica, geoquímica de solos e biogeoquímica mostrou que a assinatura desses elementos, nos três meios de amostragem, delimita o halo hidrotermal no qual se encontram os teores mais elevados de Au na área do depósito (Pulz et al. 1999).

É objetivo deste trabalho, caracterizar a assinatura biogeoquímica dos elementos Terras Raras em relação às variações destes elementos no ambiente laterítico que recobre as rochas graníticas e vulcânicas do distrito mineiro

1 - Universidade Federal do Rio Grande do Sul, Instituto de Geociências, CPGq, Centro de Estudos em Petrologia e Geoquímica, Porto Alegre (RS), Brasil. E-mail: maria.cunha@ufrgs.br 
de Pitinga, Estado do Amazonas. A partir da concentração dos ETR em Ampelozizyphus amazonicus (Família Rhamnaceae), espécie vegetal endêmica na América do Sul, de comum ocorrência na região norte do Brasil e popularmente conhecida como saracura-mirá ou cerveja de índio, visa-se um melhor entendimento dos processos inerentes à mobilidade dos ETR em ambientes supergênicos, principalmente daqueles sujeitos a intensa alteração intempérica, como é o caso da região amazônica.

MATERIAL E MÉTODOS Amostras de folhas de Ampelozizyphus amazonicus foram coletadas nas adjacências da Mina de Pitinga, região situada em área de floresta pluvial, com clima tipicamente tropical, temperatura média anual de $26^{\circ} \mathrm{C}$ e precipitação média anual de $2000 \mathrm{~mm}$ (maior período de chuvas entre dezembro e maio). Localizado a aproximadamente $300 \mathrm{~km}$ a norte de Manaus, o distrito mineiro de Pitinga se caracteriza pela presença de corpos graníticos, intrusivos nas rochas vulcânicas e piroclásticas ácidas do Grupo Iricoumé, unidade geológica de maior distribuição nesta área (Daoud 1988, Borges et al. 2003). A mina, além de ser uma das maiores produtoras mundiais de estanho, contém importantes ocorrências de criolita e de elementos como $\mathrm{Zr}, \mathrm{Nb}, \mathrm{Ta}$, Y e REE.

A seleção de Ampelozizyphus amazonicus como meio de amostragem se deu pela ampla distribuição na área da mina e pelo fácil reconhecimento, dada a sua utilização pelos habitantes da região como preventiva nos sintomas de malária.

A preferência por amostragem de folhas é feita em função de que estas contêm mais biomassa e também porque os teores dos elementos nelas contidos são, em geral, mais uniformes e proporcionais aos teores do substrato, ainda que cada planta tenha uma capacidade distinta para estocar os elementos químicos (Brooks 1972).

Conforme afigura 1, a coleta das amostras de planta foi feita nas superfícies de alteração dos granitos Madeira (Am.74;75;76;77) e Água Boa (Am.02;68;69;70;73;73.1) e na área de ocorrência das rochas vulcânicas (Am. 01, 03, $15,18,72)$ do Grupo Iricoumé.
No laboratório, as amostras da planta foram secadas em estufa a $80^{\circ} \mathrm{C}$ e após submetidas à calcinação, a uma temperatura de $450-500^{\circ} \mathrm{C}$, por um período de 6 a $8 \mathrm{~h}$. As cinzas resultantes foram digeridas com $\mathrm{HClO}_{4}^{-}$ $\mathrm{HNO}_{3}-\mathrm{HCl}-\mathrm{HF}$ e analisadas por ICP-MS nos Laboratórios ActLabs e AcmeLabs, (Canadá). Os resultados obtidos são expressos em peso de cinzas (Tab. 1).

A distribuição do padrão dos ETR é geralmente adquirida pela normalização da concentração nas amostras em relação aos condritos. No presente trabalho, os teores de ETR das amostras vegetais foram padronizados pelos valores dos ETR do condrito C1 (Evensen et al. 1978).

Os dados disponíveis de geoquímica de rocha (inéditos) foram utilizados como amostra representativa do comportamento dos ETR nas unidades geológicas ocorrentes na área de estudo.

RESULTADOS E DISCUSSÃO Considerações relativas aos processos de absorção e acúmulo dos elementos químicos pelas plantas mostram que cada espécie vegetal tem necessidades e graus de tolerância específicos. No caso dos ETR, as diferenças em sua configuração eletrônica geram propriedades que podem resultar em fracionamento dos mesmos, não somente durante o transporte no ambiente, como também no interior do vegetal (Ding et al. 2006, 2007). A absorção preferencial dos elementos terras raras leves (ETRL) em relação aos elementos terras raras pesados (ETRP), observada em alguns materiais biogênicos, é atribuída ao efeito do número de coordenação (maior nos ETRL) que predomina sobre o efeito do poder de polarização (Turner \& Whitfield 1979, apud Henderson 1984).

$\mathrm{Na}$ área da Mina Pitinga, o somatório dos ETR nas amostras vegetais ocorrentes nos solos derivados de rochas vulcânicas é bastante superior àquele obtido para as amostras coletadas nos solos derivados de rochas graníticas, a saber: $\sum$ ETR $=27,49 \mathrm{ppm}$ para os solos de rochas vulcânicas e $\sum$ ETR 7,79 ppm para os solos de rochas graníticas.

Para fins de comparação entre o padrão de dis-

Tabela 1 - Teores de ETR em Ampelozizyphus amazonicus (ppm em peso de cinzas).

\begin{tabular}{c|cccccccccc|ccccc}
\hline Elem & $68^{*}$ & $69 *$ & $70 *$ & $73^{*}$ & $73.1 *$ & $02 *$ & $74 *$ & $75^{*}$ & $76^{*}$ & $77 *$ & $01 * *$ & $03 * *$ & $15^{* *}$ & $18^{* *}$ & $72^{* *}$ \\
\hline $\mathrm{La}$ & 1 & 0,5 & 6,4 & 1,4 & 0,9 & 2,77 & 1,4 & 0,7 & 0,9 & 1,4 & 2,28 & 4,46 & 4,33 & 8,78 & 14 \\
$\mathrm{Ce}$ & 2,02 & 0,95 & 3,2 & 2,65 & 2,46 & 5,44 & 3,34 & 1,7 & 1,81 & 3,31 & 4,38 & 8,72 & 8,13 & 16,2 & 24,3 \\
$\mathrm{Pr}$ & 0,2 & 0,1 & 0,9 & 0,4 & 0,2 & 0,522 & 0,3 & 0,2 & 0,2 & 0,3 & 0,327 & 0,675 & 0,827 & 1,76 & 2,65 \\
$\mathrm{Nd}$ & 1 & 0,3 & 2,6 & 1,2 & 0,7 & 1,58 & 1,1 & 0,5 & 0,7 & 1,1 & 1,07 & 2,05 & 2,64 & 5,53 & 8,52 \\
$\mathrm{Sm}$ & 0,2 & 0,1 & 0,1 & 0,3 & 0,1 & 0,392 & 0,3 & 0,1 & 0,2 & 0,3 & 0,207 & 0,401 & 0,481 & 1,09 & 1,45 \\
$\mathrm{Eu}$ & 0,05 & 0,05 & 0,05 & 0,05 & 0,05 & 0,059 & 0,05 & 0,05 & 0,05 & 0,05 & 0,049 & 0,067 & 0,091 & 0,211 & 0,253 \\
$\mathrm{Gd}$ & 0,2 & 0,1 & 0,2 & 0,3 & 0,2 & 0,39 & 0,3 & 0,1 & 0,2 & 0,3 & 0,21 & 0,45 & 0,45 & 1,06 & 1,4 \\
$\mathrm{~Tb}$ & 0,05 & 0,05 & 0,05 & 0,1 & 0,1 & 0,095 & 0,1 & 0,05 & 0,1 & 0,1 & 0,038 & 0,079 & 0,064 & 0,153 & 0,156 \\
$\mathrm{Dy}$ & 0,3 & 0,05 & 0,1 & 0,9 & 0,4 & 0,683 & 0,6 & 0,3 & 0,4 & 0,9 & 0,235 & 0,94 & 0,352 & 0,898 & 0,752 \\
$\mathrm{Ho}$ & 0,1 & 0,05 & 0,05 & 0,2 & 0,1 & 0,144 & 0,2 & 0,1 & 0,1 & 0,2 & 0,048 & 0,106 & 0,062 & 0,171 & 0,128 \\
$\mathrm{Er}$ & 0,3 & 0,1 & 0,1 & 0,8 & 0,3 & 0,471 & 0,5 & 0,3 & 0,3 & 0,7 & 0,151 & 0,35 & 0,197 & 0,546 & 0,39 \\
$\mathrm{Tm}$ & 0,05 & 0,05 & 0,05 & 0,1 & 0,1 & 0,069 & 0,1 & 0,1 & 0,1 & 0,1 & 0,024 & 0,056 & 0,028 & 0,082 & 0,049 \\
$\mathrm{Yb}$ & 0,3 & 0,1 & 0,1 & 0,7 & 0,4 & 0,514 & 0,5 & 0,3 & 0,4 & 0,7 & 0,169 & 0,43 & 0,195 & 0,586 & 0,347 \\
$\mathrm{Lu}$ & 0,05 & 0,05 & 0,05 & 0,1 & 0,1 & 0,062 & 0,1 & 0,05 & 0,05 & 0,1 & 0,025 & 0,056 & 0,023 & 0,075 & 0,043 \\
\hline
\end{tabular}

*amostras de plantas coletadas em ambiente granítico; ** amostras de plantas coletadas em ambiente vulcânico 


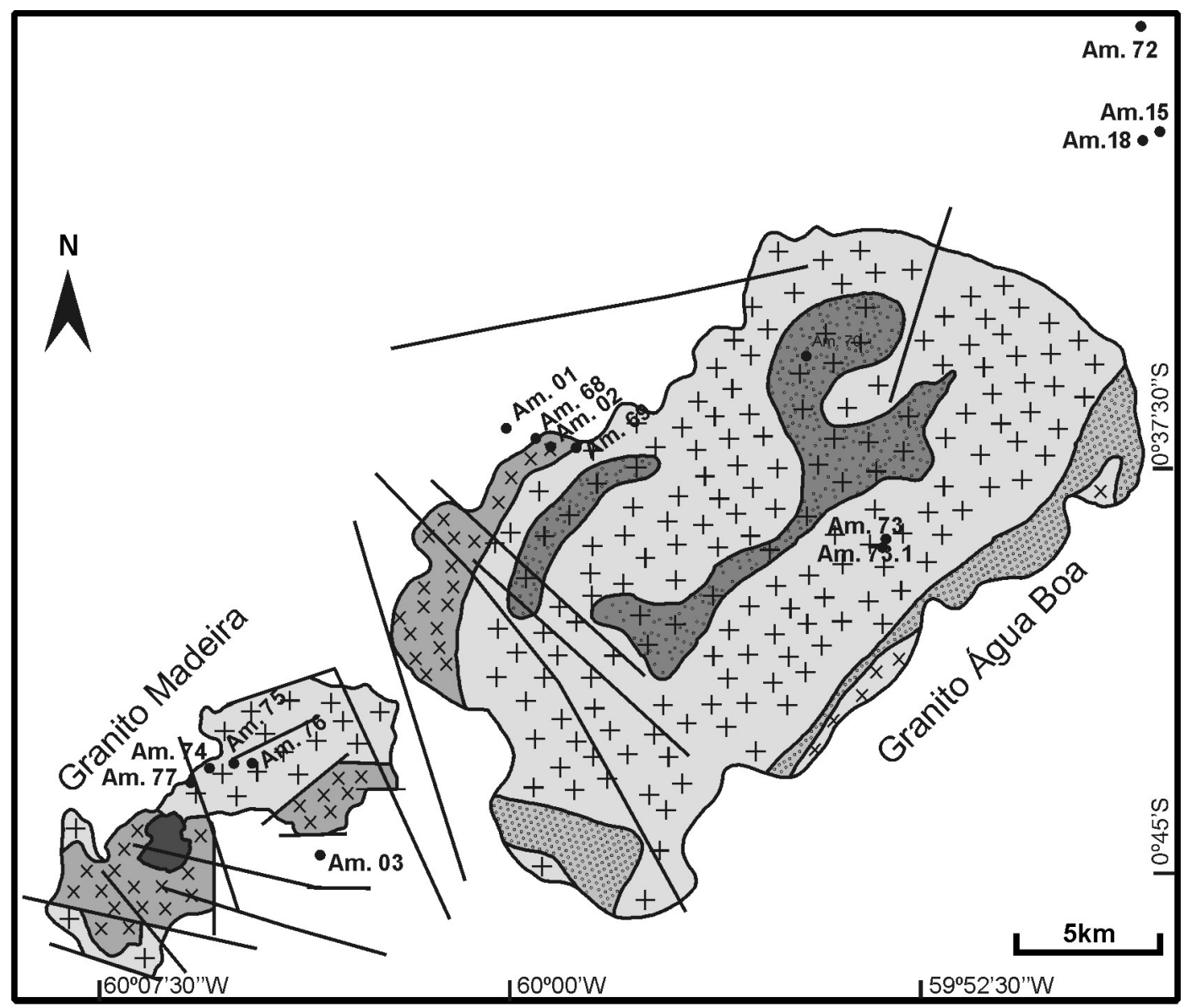

Granito Agua Boa

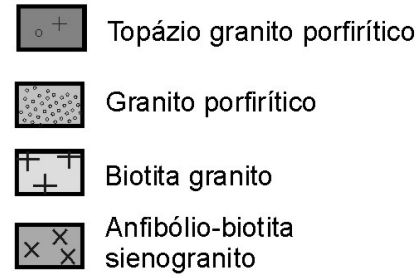

Granito Madeira

Albita granito e Granito porfirítico hipersolvus

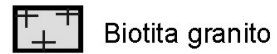

Anfibólio-biotita sienogranito

Figura 1 - Mapa geológico da área da Mina Pitinga (mod. de Lenharo et al. 2000) com a localização das estações de amostragem de exemplares de Ampelozizyphus amazonicus.

tribuição dos ETR nas plantas e nas rochas graníticas, os dados biogeoquimicos foram agrupados de acordo com a faciologia da mesmas, definida por Costi (2000).

Nas áreas graníticas, o padrão biogeoquímico dos exemplares amostrados na fácies anfibólio-biotitagranito, exibe uma distribuição dentro de uma mesma faixa de valores (Fig. 2), com razão $\mathrm{La} / \mathrm{Yb}_{\mathrm{N}}=1,50 \mathrm{e}$ com teores inferiores aos da rocha. Os valores de ETRL são mais elevados $\left(\mathrm{La} / \mathrm{Sm}_{\mathrm{N}}=3,28\right)$ que os $\operatorname{ETRP}(\mathrm{Gd} /$ $\left.\mathrm{Yb}_{\mathrm{N}}=0,37\right) \mathrm{e}$, em algumas amostras, são observadas discretas anomalias negativas de Eu.

$\mathrm{Na}$ figura 3, são destacadas duas amostras de planta, cuja configuração das curvas é muito semelhante àquela das rochas, embora com contraste menor $\mathrm{e}$ teores mais baixos.

Com relação as amostras de vegetais coletadas nos solos da fácies anfibólio-biotita-sienogranito, o padrão biogeoquímico dos ETR apresenta a mesma configuração mostrada na fácies anfibólio-biotita-granito, com razão $\mathrm{La} / \mathrm{Yb}_{N}=3,15$ e teores de ETRL mais elevados $\left(\mathrm{La} / \mathrm{Sm}_{\mathrm{N}}=3,89\right)$ que os ETRP $\left(\mathrm{Gd} / \mathrm{Yb}_{\mathrm{N}}=0,60\right)$. Nesta fácies, somente a amostra 2 apresenta um padrão muito semelhante ao padrão da rocha. Nota-se ainda que os teores de ETR nesta amostra é mais elevado que nas demais (Fig. 4).

As fortes anomalias negativas de Eu presentes nas amostras de rocha (Figs. 2 e 3), não são reproduzidas nas plantas, sendo suavizadas provavelmente já nas soluções dos solos.

Nas amostras de vegetais coletadas no solo das rochas vulcânicas (Fig. 5), os teores de ETRL são mais elevados $\left(\mathrm{La} / \mathrm{Sm}_{\mathrm{N}}=5,21\right)$ que os de $\operatorname{ETRP}\left(\mathrm{Gd} / \mathrm{Yb}_{\mathrm{N}}\right.$ 


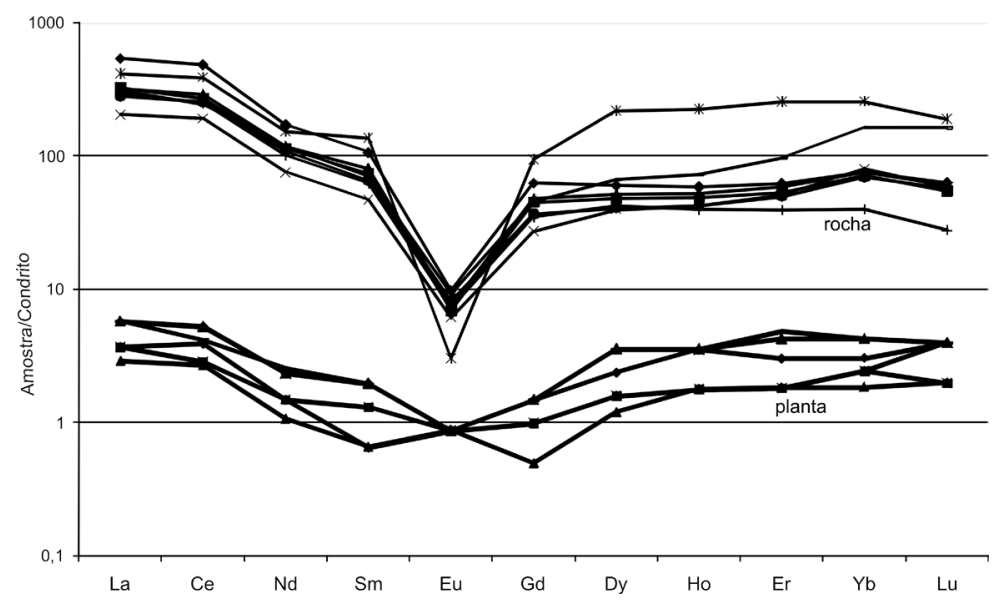

Figura 2 - Padrão biogeoquímico dos ETR em Ampelozizyphus amazonicus (amostras 73;73.1;74;75;76;77, cf.Fig.1) em relação ao padrão de rocha granitica representado por algumas amostras coletadas na fácies anfibólio-biotita-granito.

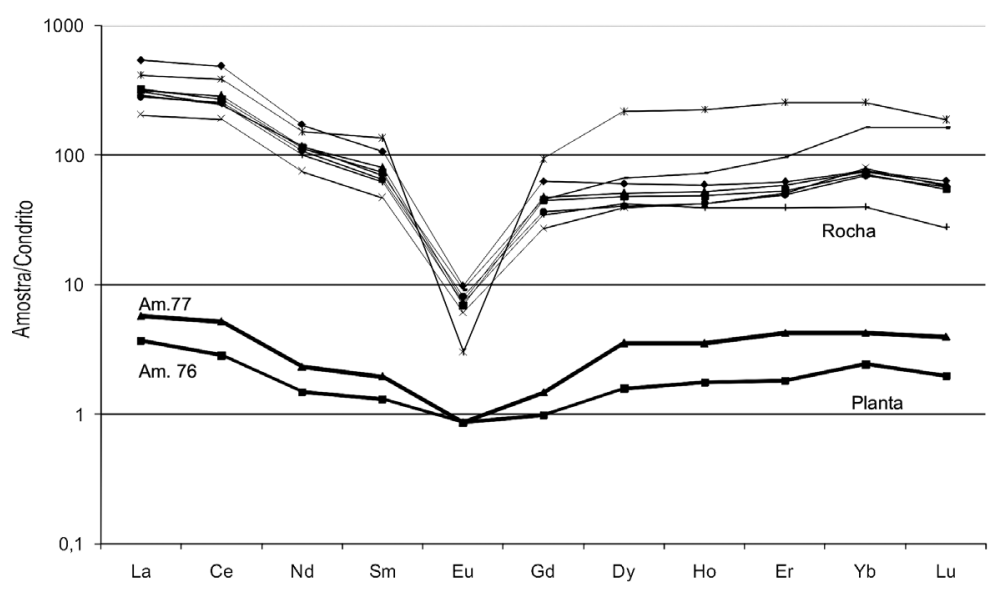

Figura 3 - Exemplo de semelhança entre o padrão de distribuição dos ETR na planta e na rocha representada por amostras da fácies anfibólio-biotita-granito.

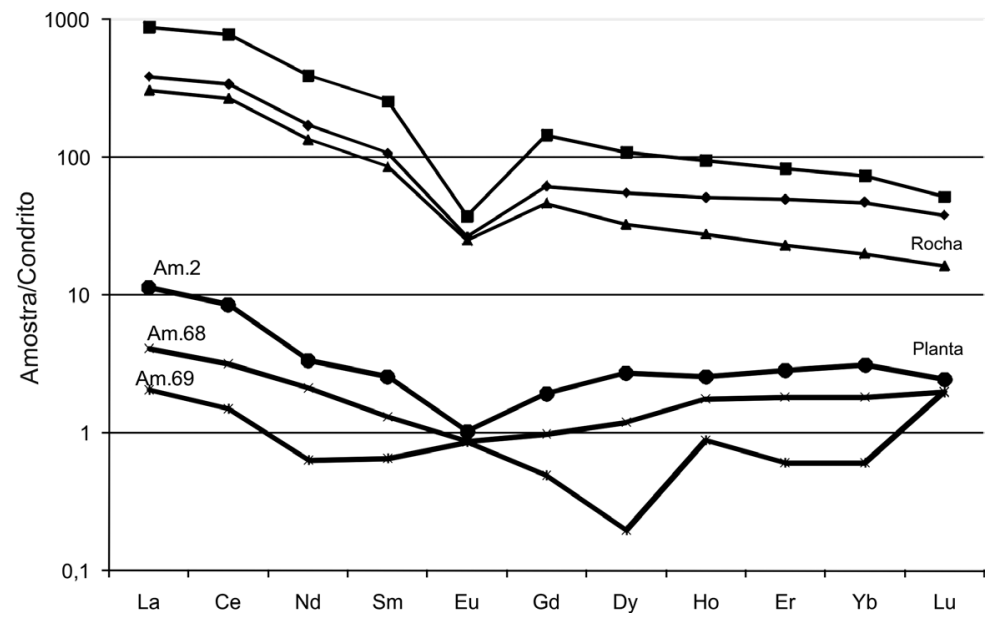

Figura 4 - Exemplo da variação do padrão biogeoquímico dos ETR em amostras de Ampelozizyphus amazonicus comparativamente ao padrão de rocha na área de ocorrência da fácies anfibólio-biotita-sienogranito). 


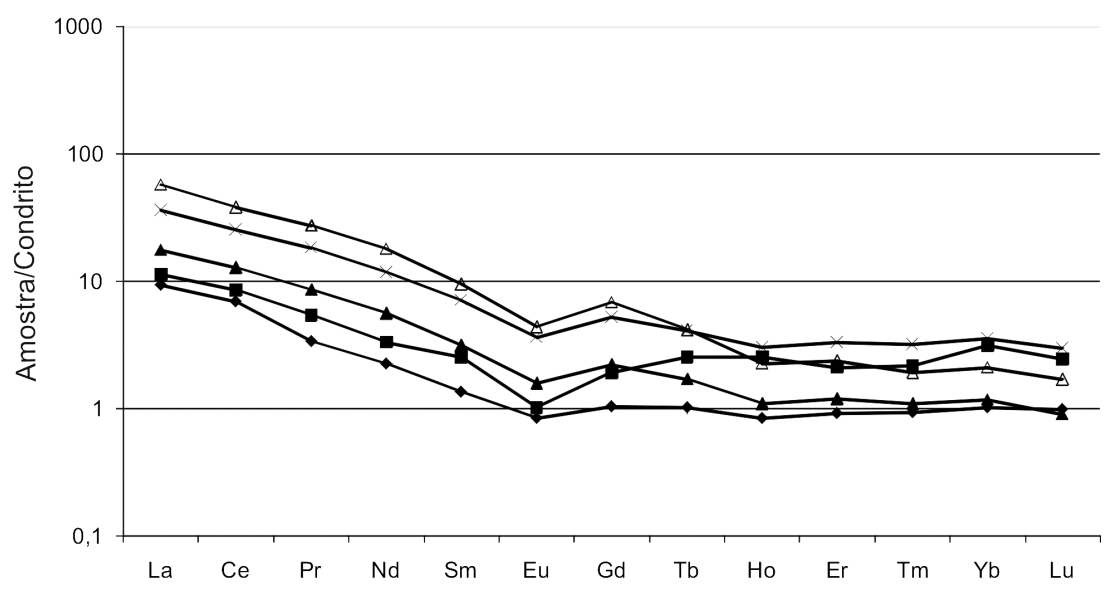

Figura 5 - Padrão biogeoquímico dos ETR em amostras (01;03;15;18;72,cf.Fig.1) de Ampelozizyphus amazonicus coletadas no solo de rochas vulcânicas do Grupo Iricoumé.

$=1,07)$, refletindo assim uma maior absorção dos ETRL pelos vegetais $\left(\mathrm{La} / \mathrm{Yb}_{\mathrm{N}}=8,22\right)$. O Eu apresenta leve anomalia negativa, com valores $\left(\mathrm{Eu} / \mathrm{Eu}^{*}=0,56\right)$ muito semelhantes àqueles obtidos por Valério et al. (2005) para os vulcanitos do Grupo Iricoumé, no município de Presidente Figueiredo, AM. Ainda, o padrão das curvas, subparalelo, é similar àquele observado por Horbe e Peixoto (2006) para as coberturas lateríticas das seqüências vulcânicas da Mina Pitinga.

$\mathrm{O}$ acesso aos dados de ETR de uma amostra de bauxita, coletada no mesmo ponto de amostragem da planta (Am.3, Fig. 1), possibilitou uma comparação entre os teores da planta e do substrato vulcânico. Observase pela figura 6 um padrão de distribuição quase idêntico, embora os valores no vegetal sejam inferiores àqueles da bauxita. Nos dois casos, as curvas dos ETRL são descendentes, com razão $\mathrm{La} / \mathrm{Yb}_{\mathrm{N}}$ de 8,22 na planta e de 8,51 na bauxita, e tendendo ao paralelismo nos ETRP.
A semelhança entre o padrão de distribuição dos ETR na planta e o padrão das rochas permite supor que também os materiais de alteração dos perfis lateríticos da Mina Pitinga refletem o padrão herdado da rocha mãe. Por outro lado, o comportamento anômalo de algumas curvas biogeoquímicas, como observado nas figuras 2 e 4, poderia ser, em parte, decorrente da atividade de substâncias trocadoras de íons e de compostos orgânicos quelantes presentes nas soluções que percolam o solo, originando algum fracionamento nos ETR, o qual é reproduzido pela planta. A amostra 69 (Fig. 4) apresenta um comportamento anômalo do Ho e do Lu que pode ser relacionado ao efeito tétrade com a formação de complexos mais solúveis destes elementos, disponibilizando-os em maior quantidade para os vegetais. Este fracionamento, não observado no substrato, pode ser originado pela própria planta durante o processo de absorção.

De acordo com Robinson et al. (1958), os ETR

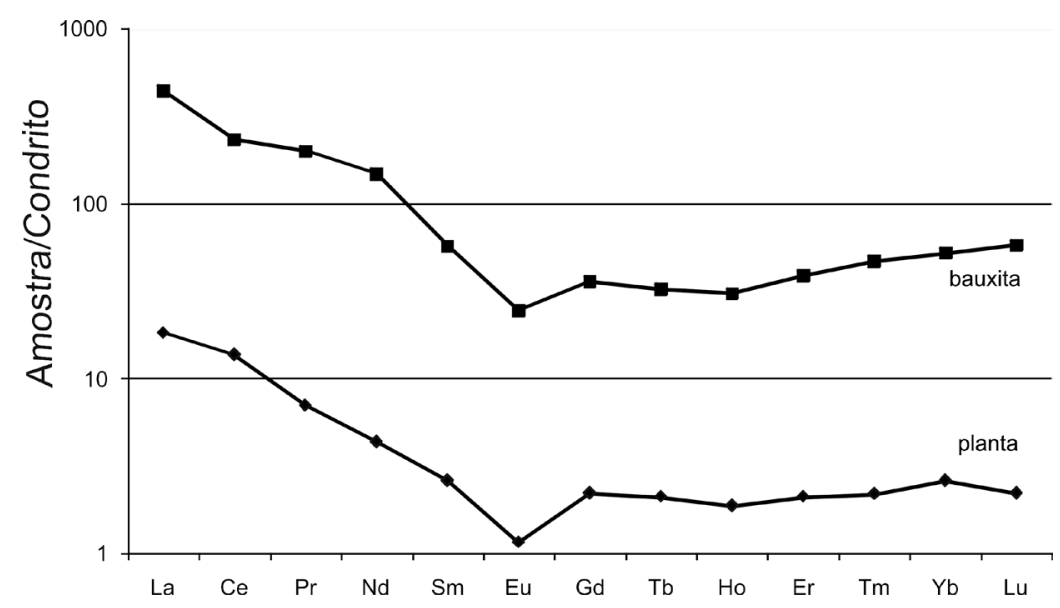

Figura 6 - Comparação entre as curvas de distribuição dos ETR em amostra de bauxita sobre rochas vulcânicas e de planta, ambas coletadas no ponto 03 da figura 1. 
não ocorrem nas soluções do solo como íons, e sim na forma de agregados quasicolóides que podem ser separados por ultrafiltração ou precipitação. Se estes elementos se concentram como quasicolóides nas águas subterrâneas, provavelmente precipitarão na medida em que a água se move através do solo e do saprólito, embora a maior parte deles possa permanecer em solução por ação das substâncias orgânicas presentes no meio, sendo possivelmente esta a forma mais plausível de assimilação pelas plantas.

Nas camadas mais superficiais dos perfis bauxíticos que se desenvolvem na área das rochas vulcânicas de Pitinga, predominam materiais argilosos e sílticos, em relação aos grãos tamanho areia, mais abundantes nos perfis graníticos (Horbe \& Peixoto 2006). Este fato pode explicar o maior enriquecimento (Fig. 5) e a semelhança entre o padrão de distribuição dos ETR no solo e nas plantas (Fig. 6), as quais teriam maior capacidade de troca iônica com as argilas lateríticas, o que não ocorre nos solos sobre as rochas graníticas, nas quais os minerais acessórios, como o zircão, retêm os ETR. Estudos em perfis lateríticos de rochas graníticas da região de Pitinga mostram que o zircão é muito pouco alterado, mesmo em locais com elevada taxa de lateritização, o que corrobora com o descrito acima.

A semelhança na configuração das curvas biogeoquímicas (Fig. 5) com aquela do solo bauxítico (Fig. 6) sugere que as plantas reproduzem padrão de distribuição dos ETR das superfícies de alteração do ambiente vulcânico, e estas, por sua vez, devem reproduzir de modo similar o padrão de distribuição dos ETR nas rochas. Segundo Horbe \& Peixoto (2006), o teor de ETR na Mina Pitinga aumenta nas camadas representadas pelos Oxisolos (profundidades entre 2 e $5 \mathrm{~m}$ ), cujas características geoquímicas estão diretamente relacionadas com a rocha fonte, uma vez que se desenvolveram sob as mesmas condições de intemperismo e de drenagem.

Com relação ao fracionamento, estudos sobre a concentração de ETR em vegetais ocorrentes no maciço alcalino-carbonático de Catalão I, Goiás (Lima e Cunha et al. 1993) indicam a inexistência de um fracionamento conspícuo dos elementos da série, embora haja um enriquecimento em ETRL na espécie estudada (Solanum lycocarpum), o que condiz com Evans (1990) ao afirmar que as plantas absorvem os ETR sem fracioná-los, ou mostrando um enriquecimento seletivo em ETRL.

De acordo com Robinson et al (1958) a absorção dos ETR depende tão somente da sua biodisponibilida- de no solo, ou seja, o vegetal não teria o poder de discriminar os diversos membros da série, assimilando-os substancialmente na proporção em que estão disponíveis no meio. A afirmativa destes autores é baseada na similaridade de concentração dos ETR na planta e nos complexos de troca do solo, indicando que o vegetal não atua como um agente fracionador, fato este condizente com o observado na figura 6. No entanto, estudos mais recentes (Wang et al.1997, Ding et al. 2006) sugerem que os ETR podem efetivamente ser fracionados durante seu processo de absorção pelas plantas ou ainda no transporte destes na biomassa do vegetal sendo, neste caso, reflexo de um ambiente químico interno (reações de ligantes orgânicos no interior da planta). O comportamento anômalo do Ho e do Lu na amostra 69 (Fig. 4), que pode ser relacionado ao efeito tétrade, sugere um exemplo de fracionamento de alguns elementos da série pela própria planta.

\section{CONCLUSÕES}

1. Na área da Mina Pitinga, os exemplares de Ampelozizyphus amazonicus amostrados nos solos vulcânicos têm teores de ETR significativamente mais altos que aqueles obtidos pelas amostras de vegetais coletadas em solos de rochas graníticas, o que é interpretado como decorrência da maior biodisponibilidade dos ETR nos solos de origem vulcânica.

2. A semelhança entre a assinatura biogeoquímica dos ETR em Ampelozizyphus amazonicus e o padrão das rochas, principalmente das rochas vulcânicas, sugere que os materiais de alteração dos perfis lateríticos da Mina Pitinga refletem o padrão herdado da rocha mãe.

3. A configuração anômala de algumas curvas biogeoquímicas das amostras de planta coletadas nos solos de rochas graníticas pode ser decorrente da forma como os ETR se encontram nas soluções do solo de onde a planta os retirou, visto que em sistemas geoquímicos aquosos estes elementos podem formar complexos, alterando assim sua mobilidade, provocando seu fracionamento, ou de processos intrínsecos à própria planta capazes de fracionar os elementos da série, independente das propriedades químicas dos ETR no substrato.

4. Estudos que visem um melhor entendimento dos processos inerentes ao comportamento dos ETR em ambientes supergênicos são necessários, principalmente em regiões sujeitas a intensa alteração intempérica, como é o caso da região de abrangência da Mina Pitinga.

\section{Referências}

Borges R.M.K., Dall'Agnol R., Costi H.T. 2003. Geologia, Petrografia e Química Mineral Micas dos Greisens Estaníferos Associados ao Pluton Água Boa, Pitinga (AM) Rev. Bras. Geoc., 33(1):51-62

Brioschi L., Steinmann M., Lucot E., Pierret M.C., Stille P., Badot P.M. 2009.Absorption and fractionation of REE by vegetation: A comparative field study on plants grown on granite, carbonate, and carbonatite. In: Goldschmidt
Conference, Abstracts, p.A161.

Brooks R.R. 1972. Geobotany and Biogeochemistry in Mineral Exploration. New York, Harper \& Row Pub, $289 \mathrm{p}$.

Costi H.T. 2000. Petrologia de Granitos Alcalinos com Alto Flúor Mineralizados em Metais Raros: o Exemplo do Albita Granito da Mina Pitinga, Amazonas, Brasil. Tese de Doutoramento, Universidade Federal do Pará, 345 p. 
Daoud W.K.1988. Granitos Estaniferos de Pitinga, Amazonas: contexto geológico e depósitos minerais associados. Dissertação de Mestrado, 194p. Universidade de Brasília.

Ding S.M., Liang T., Zhang C.S., Yan J.C., Zhang Z. 2005. Accumulation and fractionation of rare earth elements (REEs) in wheat: controlled by phosphate precipitation,cell wall absorption and solution complexation. Journal of Experimental Botany, 56(420):2765-2775.

Ding S., Liang T., Chaosheng Z., Zechun H., Yaning X., Tongbin C. 2006. Fractionation Mechanisms of Rare Earth Elements (REEs) in Hydroponic Wheat: An Application for Metal Accumulation by Plants. Environ. Sci.Technol., 40:2696-2691.

Ding S., Liang T., Yan J.C., Zhang Z., Huang Z.C., Xie Y.N. 2007. Fractionations of rare earth elements in plants and their conceptive model. Science in Chine Series C: Life Sciences, 50(1):47-55

Dunn C. E. 1983b. Biogeochemical Investigations in the northern Saskatchewan: preliminary data on tungsten, gold, platinum, rare earth and uranium. In: Summary of investigations (1983) Saskatchewan Geological Survey, Sak Energy Mines, Misc. Rep., 83:106-122.

Evans C.H.1990. Biogeochemistry of the Lanthanides. Plenum Press, v.8, 444 p.

Evensen N.M., Hamilton P.J., O'nions R.K. 1978. Rare earth abundances in chondritic meteorites. Geochim. Cosmochim. Acta, 42:1199-1212.

Henderson P. 1984. Rare Earth Elements Geochemistry. Developments in Geochemistry, Elsevier, Amsterdam, v.2, 510p.

Horbe A.M.C \& Peixoto S.F. 2006. Geochemistry of Pitinga Bauxite Deposit - Amazonian Region - Brazil. In: Fitzpatrick R.W. \& Shand P. (eds.) Regolith Consolodation and Dispersion of Ideas. In: The CRC Leme Regolith Symp., Hahndorf Resort, South Australia, Proceedings, p. 144-146.

Kabata-Pendias A. \& Pendias H. 1984. Trace Elements in Soils and Plants. CRC Press, Florida, 315p.

Lenharo S.L.R., Pollard P.J., Born H. 2000. Matrix rock texture in the Pitinga Topaz Granite, Amazonas, Brazil. Rev. Bras. Geoc., 30(2):238-241.

Lima e Cunha M.C., Formoso M.L.L., Pereira V.P. 1993. Biogeoquimica dos elementos terras-raras no Complexo Alcalino-Ultramafico de Catalao I, Goias. Geochim. Bras., 7(2):101-111.

Lottermoser B.G. 1990. Rare earth elements mineralization whitin the Mt Weld carbonate laterite, Western Australia. Lithos, 24:151-167

Markert B., Piehler H., Lieth H., Sugimae A. 1989. Normalization and calculation of lanthanide element concentrations in environmental samples. Radiation and Environmental Biophysics, 28(3):213-221.

Milton M.C., Murata K.J., Knetchel M.K. 1944. Weinschenkite, yttrium, phposphate dehydrate fromVirginia. American Mineralogist, 29:92-107.

Nesbitt H.W. 1979. Mobility and fracctionation of rare earth elemens during the weathering of a granodiarite. Nature, 279:206-210.

Pulz G.M., Barboza E.S., Lima e Cunha M.C., Fernandes C.J., Pinho F.E., Quadros A.P., Sobral M. 1999. Estudo Comparativo dos Elementos Terras Raras e Ouro na Prospecção Litogeoquímica, Geoquímica do Solo e Biogeoquímica na área do Depósito Pau-A-Pique, Grupo Aguapeí, Oeste de Mato Grosso. In: Sociedade Brasileira de Geoquímica, Congresso Geoquímica dos de Países Língua Portuguesa, 5 e Congresso Brasileiro de Geoquímica 7, Porto Seguro, Anais, São Paulo, Anais, 1:635-637.

Robinson W.O., Bastron H., Murata K.J. 1958. Biogeochemistry of the rare earth elements with particular reference to hickory trees. Geochim. Cosmochim. Acta, 14(1/2):55-67.

Topp S.E., Salbu B., Roaldset E., Jorgensen P. 1984. Vertical distribution of trace elements in laterite soil (Suriname). Chem. Geol., 47 (1/2):159-174

Valério C.S., Souza V.S., Macambira M.J.B., Milliotti C.A., Carvalho A.S. 2005. Geoquímica e Idade $\mathrm{Pb}-\mathrm{Pb}$ do Grupo Iricoumé da Região da Borda Norte da Bacia do Amazonas, Município de Presidente Figueiredo (Am). In: Simpósio de Vulcanismo e Ambientes Associados, 3, Cabo Frio, RJ., Atas, p. 47-52.

Wang Y.Q., Sun J.X., Chen H.M.F., Guo Q. 1997. Determination of the contents and distribution characteristics of REE in natural plants by NAA J.Radioanal. Nucl. Chem., 219(1):99-103.

Wang Z.J, Liu D.F, Lu P., Wang C.X. 2001. Accumulation of rare earth elements in corn after agricultural application. Journal of Environmental Quality, 30:37-45.

Manuscrito ID 11580

Submetido em 25 de junho de 2008 Aceito em 23 de junho de 2009 